\title{
Esophagogastric fistula: a rare complication of laparoscopic Nissen fundoplication
}

\section{Paraskevas Gkolfakis ${ }^{a}$, John Katsogridakis ${ }^{b}$, Dimitrios Schizasc, loannis S. Papanikolaou ${ }^{a}$}

Attikon University General Hospital, Medical School, National and Kapodistrian University of Athens; Gastroenterology Unit of Athens; Laikon General Hospital, National and Kapodistrian University of Athens, Athens, Greece

A 39-year-old Caucasian male, who had suffered since the age of 19 years from gastroesophageal reflux disease and had undergone laparoscopic Nissen fundoplication with initial resolution of his complaints four years earlier, presented with worsening of heartburn and a new onset of dysphagia. Endoscopy detected an ulcerated fistula orifice on the z-line. Retrograde vision revealed intact Nissen fundoplication and the distal orifice of the aforementioned fistula in the funduscorpus transition area (Fig. 1). Biopsies from the ulcer were negative and the patient was treated with long-term highdose proton pump inhibitors. Two months later on followup endoscopy a clean small proximal fistula orifice in the esophagus and a distal one in the stomach (Fig. 2) were detected.

Esophagogastric fistula or "double lumen esophagus" is a rare complication of both open and laparoscopic Nissen fundoplication. Regarding laparoscopic anti-reflux surgery we present the fifth case of this unusual complication [1-3]. Overall, pathogenetic causes include prolonged untreated reflux disease with ulcerations and erosions, migration of the wrap, intraoperative injuries, ischemic necrosis, tissue reaction with used sutures or Teflon pledgets, and local existing malignancy or prior surgery [2]. When symptomatic, esophagogastric fistula can be treated conservatively with anti-secretory agents or endoscopically with clip application (either through or over the scope); for non-responding cases laparoscopic gastroplasty or even open surgery could be an option [3].

${ }^{\text {a}}$ Hepatogastroenterology Unit, Second Department of Internal Medicine - Propaedeutic, Research Institute and Diabetes Center, Medical School, National and Kapodistrian University of Athens, Attikon University General Hospital (Paraskevas Gkolfakis, Ioannis S. Papanikolaou); ${ }^{\mathrm{b}}$ Gastroenterology Unit of Athens, Athens (John Katsogridakis); 'First Department of Surgery, Laikon General Hospital, National and Kapodistrian University of Athens (Dimitrios Schizas), Athens, Greece

Conflict of Interest: None

Correspondence to: Paraskevas Gkolfakis, MD, Hepatogastroenterology Unit, 2nd Department of Internal Medicine and Research Unit, Attikon University General Hospital, Medical School, National and Kapodistrian University of Athens, Rimini 1, 12462 Athens, Greece, +30210 5832089, e-mail: pgkolfakis@med.uoa.com

Received 22 May 2016; accepted 10 June 2016; published online 6 Sepember 2016

DOI: http://dx.doi.org/10.20524/aog.2016.0078

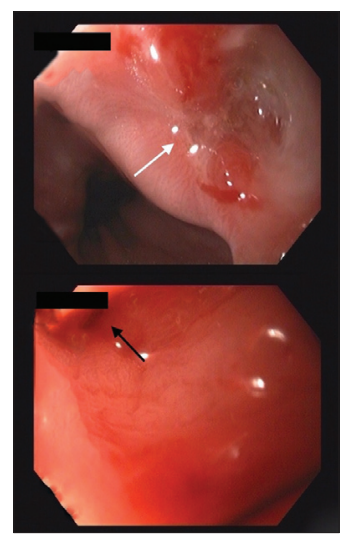

Figure 1 Endoscopy images during the first postoperative control. The white arrow indicates the ulcerated proximal esophageal orifice of the fistula, while the gastric orifice can barely be seen during retrograde vision (black arrow)

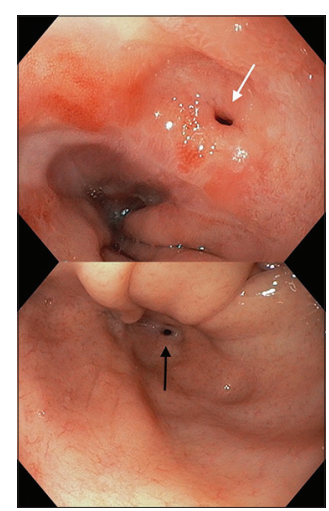

Figure 2 Endoscopy images after two months on proton pump inhibitor treatment. The healed proximal (white arrow) and distal orifices (black arrow) of the fistula are demonstrated in forward and retrograde vision, respectively

\section{References}

1. Baladas HG, Smith GS, Richardson MA, Dempsey MB, Falk GL. Esophagogastric fistula secondary to teflon pledget: a rare complication following laparoscopic fundoplication. Dis Esophagus 2000;13:72-74.

2. Chun CL, Dunnington G, Triadafilopoulos G. Where is the acid coming from? Esophago-gastric fistula following laparoscopic Nissen fundoplication. Dig Dis Sci 2013;58:1486-1490.

3. McKenna DT, Ziegler K, Selzer D. Laparoscopic transgastric gastroplasty: a novel technique for a large esophagogastric fistula. J Laparoendosc Adv Surg Tech A 2014;24:574-577. 